\title{
Escravos de Jó, KANBAN e L.E.R.
}

\section{Leda Leal Ferreira}

Divisão de Ergonomia- FUNDACENTRO

Rua Capote Valente, 710- São Paulo- SP- 05409-002

\author{
Palavras chaves: Lesões por Esforços Repetitivos- L.E.R., \\ "just-in time", indústria metalúrgica, intensificação do trabalho.
}

\author{
Key words: repetitive strain injury, just-in-time, metal industry, \\ intensification of work.
}

\section{RESUMO}

Casas de tenossinovite numa empnesa metalúngica foram analisados através da Análise Coletiva do Trabalho, da qual participaram tneze trabalhadores e o Sindicato da categoria. A partir da descriçäo de sua atividade de trabalho, feita em duas reuniöes coletivas, ficou claro que a tenossinovite era um termo geral utilizado para várias queixas (dores, formigamento, perda de força) dos membros superiores e inferiores que acometiam os trabalhadores. O problema atingia trabalhadores de vários setores da empresa, cujas tanefas exigiam movimentos estereotipados, localizados e repetidos dos braços ou pernas e um ritmo de trabalho elevado. Os casos aumentaram quando houve uma reorganizaçäo da produção da empresa, com a introdução de células de produção, Kanban e polivaléncia dos operários, reorganização que foi apresentada aos trabalhadores sob a nome de "Escravos de Jó". $O$ artigo termina com comentários sobre a intensificaçäo do trabalho, no Brasil e no mundo, provocada pelas novas formas de organização da produção e a necessidade de levá-la em consideração nos estudos técricos sobre a gênese das L.E.R.

\section{ABSTRACT}

Tenosynovitis cases in a metal plant were studied using the Collective Work Analysis, involving 13 workers and their union. From the description of their work activities, during two group meetings, it became clear that tenosynovitis was a generic term used to describe several complaints (pains, loss of strenght) of the the superior and inferior limbs, suffened by the workers. The problem afflicted workers of several sectors of the company, whose tasks required stereotyped, repetitive and localized movements of the arms or legs and a high work rate. The number of cases rised when the company reonganized its production, introducing productions cells, Kanban and multivalence of workers, reorganization presented to the workers under the name of "escravas de Jó". The paper ends with comments on the intensification of work, in Brazil and in the world, triggered by the new ways of organizing the production and the need to take that in consideration in the technical studies on the genesis of repetitive strain injury. 


\section{Introdução}

$O$ presente texto se insere no conjunto de estudos empíricos sobre as Lesões por Esforços Repetitivos- L.E.R., que têm sido feitos e/ou publicados recentemente, no Brasil, em diferentes setores de atividades e profissōes, como os digitadores (Assunção e Rocha,1993, Crespo Merlo, 1997), bancá rios (Ribeiro,1995; Lima, 1997, Sznelwar e Masseti, 1997), telefonistas (Echternacht, 1997), trabalhadores em restaurantes (Lima, 1997, Assunçāo, 1998) trabalhadores em indústrias metalúngicas (Cândido, 1997), de papel e papelão (Barreira, 1995), farmacêutica (Barreira, 1994) entre outros.

Trata-se de um estudo realizado em 1991, por solicitaçāo do Sindica to de Trabalbadores nas Indústrias Mecânicas e de Material Elétrico de Osasco, SP, preocupado com o grande número de casos de "tenossinovite"l entre trabalbadores de u ma das empresas metalúrgicas de sua base. Na verdade, o sindicato havia nos solicitado a realização de um "estudo ergonômico" nesta empresa. Porém, tendo em vista o papel da Fundacentro e as possibilidades reais de sua atuação, houve uma contraproposta: não faríamos tal estudo mas poderíamos auxiliar o sindicato no esclarecimento do problema que gerara a sua solicitaçāo. Aceita a proposta, o estudo foi desenvolvido, findo o qual um relatório foi entregue ao Sindicato, contendo algumas consideraçōes e recomendaçōes (Ferreira, 1992) .

\section{Método}

O método utilizado foi o da Análise Coletiva do Trabalho- ACT- (Ferreira, 1993). Trata-se de um método de análise da atividade de trabalho que se inspira na Análise Ergonômica do Trabalho -AET (Wisner, 1994), da qual utiliza a idéia central: a atividade real em situação de trabalho. Mas, ao contrário do que se passa na $\mathrm{AET}$, feita por pesquisadores com a participação dos trabalhadores, na ACT a análise é feita pelos trabalhadores, com a participação dos pesquisadores. Além disso, a ACT se interessa pelo próprio processo de análise, como um fenômeno em si, com características e dinâmicas próprias. Nesse sentido (Ferreira, 1997) se aproxima bastante das preocupaçōes da Psicodinâmica do Trabalho, de Christophe Dejours (1988).

O ponto central da ACT é a descrição da atividade pelos próprios trabalhadores. Ela é feita em grupo, em reuniões que acontecem fora do local e do horário de trabalho. Todos os participantes são voluntários e seu anonimato é garantido. $\mathrm{O}$ objetivo das reuniōes é bem preciso: cada participante deve explicar, aos outros colegas e aos pesquisadores, no que consiste a sua atividade. A pergunta condutora "O que você faz no seu trabalho?" deve ser respondida o mais detalhadamente possível, a partir de outras perguntas que vão sendo feitas no decorrer da reuniāo, com o objetivo de facilitar a compreensão dos participantes sobre o trabalho descrito.

No presente caso, foram realizadas 
apenas duas reuniōes coletivas, de cerca de duas horas cada uma, com trabalhadores acometidos de "tenossinovite". As reuniōes aconteceram na sede do Sindicato, com a presença de um de seus diretores e de dois pesquisadores. Todos os trabalhadores que participaram (treze empregados da empresa) foram voluntários e seu nome foi mantido em sigilo. Nas reunióes, cada um dos presentes relatava o trabalho que exercia e as queixas que apresentava. As reuniōes foram gravadas, com o consentimento dos participantes. Em seguida, as fitas foram transcritas por uma das pesquisadoras.

No presente texto, manteve-se a linguagem empregada nos relatos da cada trabalhador. Em muitos casos, as descrições do trabalho foram acompanhadas por gestos para explicar um movimento feito ou a localização de alguma dor, o que está registrado no texto.

\section{A tenossinovite $e$ a atividade de trabalho}

A atividade realizada pelos trabalhadores pode ser apreendida pelos relatos que serão apresentados a seguir, escolhidos entre vários diálogos:

"Eu trabalhava na parafusadeira. Eu peguei (a tenossinovite) na mão direita, que é onde eu fazia força."

Operária, 44 anos.

"Eu trabalhava no solenóide, na montagem...

- Como é?
- A gente faz o mesmo movimento do braço. Ergue o braço (direito) assim e dói bastante (faz o gesto)...pöe a peça no dispositivo e aí vai colocando tudo...Com a mão esquerda, a gente segura a peça, para ela não sair fora. Movimenta mais a [mão] direita...Dependendo do pedido, a gente chega a fazer 1300 peças e é muito corrido. E também, depois que a gente pega a prática, mesmo que queira trabalhar devagar nâo consegue. É muito movimentado."

Operária, 22 anos.

"Começou a doer o meu braço quando eu fui desmontar wafer. Tinha que fazer um esforço com o martelo, era duro e aí começou a doer o ombro.

- O que você fazia, o que é wafer?

- São três lâminas. Eu pegava aqui, colocava ali e batia com o martelo (faz os gestos) ... Depois eu fui para o escapamento. Quando o braço começou a inchar, foi no escapamento, porque era um movimento muito rápido.

- Como você fazia o escapamento?

- São bastante itens, são nove itens. Tinha que fazer rapidinho...em uma chapinha assim, compridinha, que tem vários orifícios...você encaixa ela na máquina e você vai colocando as pecinhas, cada uma encaixa num orificio. Aí, você empurra ela para dentro da máquina, aperta o batão e a máquina vem e prensa.

- Quantas peças você fazia?

- Da última vez, meu braço estava doendo e o homem mediu meus segundos e disse que eu estava montando em 25 segundos o escapamento".

Operária, 20 anos 
"O meu problema eu peguei depois que fui trabalhar nas prensas, na estamparia. Eu trabalhava numa prensa onde o certo era fazer um revezamento: eu trabalhar num dia e a outra pessoa trabalhar no outro dia, por que a prensa é alta e então o movimento é este aqui (faz o gesto): coloca a peça, bate ela, depois dobra, depois tira e coloca outra. Produção: 4 mil por dia. É um serviço bem corrido. Eu chegava a fazer até 4500...Então, foi onde eu comecei a pegar o problema. Eu sentia dor aqui (cotovelo) e ela foi subindo (braço, ombro $e$ escápula)...Tinha um colega que revezava comigo e pegou a mesma prática que eu. Só que ele se acidentou. Ele perdeu metade do dedo lá, na outra prensa e como ele está até hoje afastado, eu tive que ficar sozinho. Foi depois disso que eu comecei a sentir as dores. Fiquei dez dias afastado, fui ao médico, coloquei goteira, tomei remédio, comecei a fazer fisioterapia. Quando voltei a trabalhar; o líder me colocou em outra prensa, de pedal, só no pedal...É o tipo de uma bobinadeira, ela traz a lâmina sozinha, é só pisar no pedal. Mas não é sempre que eu trabalho nessa prensa, não é todo o dia que tem serviço lá. Quando nāo tem,o lider me põe em outra prensa....E começou a doer também o pé direito. No braço, eu sinto dor direto..."

Operário, 24 anos.

"Eu peguei a tenossinovite no teste. Eu trabalhava no setor de motor, eu fazia o teste de motor. É um serviço leve, só que...Eu tirava o motor do cavalo, botava para ver se ele estava girando normal, depois eu colocava lá uma chapinha.

- Qual é o seu problema?

- Na mäo direita, onde eu forçava.

- Era duro?

- Não.

Operária, 21 anos.

"Durante um ano montei solenóide. Não sentia nenhuma dor. Aí, mudei de seção e fui para a bobinadeira. Comecei a fazer muito movimento com o braço para enrolar o fio. (Com a mão esquerda) passava o fio atrás da bobina e enrolava. Ai, comecei a sentir dor aqui( braço esquerdo), minha mão começou a inchar e ficou um buraco bem no meio do pulso. Depois de seis meses começou a doer, porque tinha que dar produçäo de 1200 peças por dia. Agora a dor está passando para o braço direito.

- Você continua no mesmo posto?

- Não, agora eu mudei de serviço, mas de tanto forçar esta mão (direita), a dor está passando para cá. Agora estou no longlife...

- O que você faz?

- Não sei explicar bem. É um dispositivo de chumbo, porque ele pesa. $O$ longlife é quadrado só que a peça que eu pego é redonda. Eu a encaixo no dispositivo e vou fazendo movimento com o braço para bater, para arrumar...agora tenho problema nesse braço (direito)."

Operária, 25 anos

"Meu problema começou no ventilador, com dois anos na empresa $e$ um ano no ventilador. $O$ serviço era montar o pivô e então eu fazia vários movimentos...Era uma peça pequena $e$ 
várias outras peças para se colocar dentro. Depois deste pivô montado, tirava as peças daqui (faz o gesto), levava para o pedestal, apertava com a parafusadeira, que é tipo de um revólver, trepida muito. Dai, surgiu na mäo direita... Fui afastado, voltei a trabalhar, só que sai do pasto, fui para o teste do ventilador. Só que o teste funcionava com a mão esquerda. Eu pegava o ventilador aqui, colocava pra cá, testava, tirava e colocava no chäo (faz as gestos). Começou a piorar a mão esquerda...O médico pediu para mudar de serviço, eu fui para o torno. Agora, estou no torno, usinagem de peças. Só que os movimentos são rápidos...A peça vem numa calha, você pegava a peça aqui, colocava seis arruelas, usinava, tirava, colocava na linha...Isso, numa base de 1800 peças por dia. Ai, começou a adormecer a mão direita. Dai, sai deste torno e fui para outro torno. Esse, não tem que colocar arruela, só que tem movimento. Você pega a peça aqui embaixo, coloca no torno; tem uma manivela para você abrir, tem que abrir o torno, colocar a peça, depois você roda, fecha de novo, mexe na alavanca, tira a peça e coloca na caixa. Agora são 800 peças por dia."

Operário, 23 anos

"Meu problema começou quando eu trabalhava na variflex. A gente faz timer para máquina de lavar roupa. Eu trabalhava de manhã no painel, testava os timers, com outras pessoas; depois de um certo tempo, eu passei para a tarde. Ai, eu ficava sozinha à tarde, testando as peças que sobravain, que o pessoal da manhä näo conseguia testar[...].O meu jeito de trabalhar é assim: o timer tem um motor em cima, entäo você segura. Eu pegava seis, sete peças, que é o ritmo que o pessoal tem que trabalhar... Você segurava pelo fio, colocava perto do painel, com este movimento (faz o gesto): pega com a mäo esquerda, puxa o fio para trás e encaixa lá no painel e aí você vem com o fiozinho. São trinta peças, quatro painéis; nos quatro, cabem trinta cada um. Depois que eu acabava, quase na hora da janta, eu embalava as peças $e$ ia para a seção de motor....Então, era aquela correria. Aí, começou o meu braço a inchar, porque o movimento é semelhante, só que o motor é mais leve $e$ o timer é mais pesado.

- Onde dói?

- É a mão esquerda, onde encaixo e tiro. A mão direita, só usava para ligar o fiozinho no painel.

- Você é canhota?

- Não, foi o jeito que me ensinaram a trabalhar e eu acabei aprendendo.

- Quanto você faz por dia?.

- Bom, ficava uns 400 no variflex e no motor, a gente sempre testa 1000, 1200 peças, quando näo sai mais..."

Operária, 22 anos.

"Eu trabalhei, numa época, na parafusadeira. Eu sentia um pouco de dor. Comecei a reclamar, eles me tiraram dai e me colocaram no ventilador e eu näo senti mais nada. Daí, o setor parou e passaram a gente para o pressostato...São uma lâminas pequenas, porque tem que bater o contato de prata numas pecinhas de prata. Eu tenho que ficar nesta posição 


\section{PRODUÇÃO}

(faz o gesto). Tem que fazer bastante lâminas: bato com esta (mäo direita) e o pé também, lá embaixo, no pedal...Quer dizer, aqui eu ponho a peça e lá em baixo eu bato, para calibrar o contato ( faz o gesto)...E de tanto ficar assim, eu fui sentindo dor aqui ( mão direita), foi comendo no pescoço e eu comecei a reclamar. Nisso, eu tive que ir também para outra máquina, bater o primeiro terminal no casco. Tem que apertar isso aqui ( faz o gesto).(...J.Um dia, eu falei para a minha lider:- não posso trabalhar mais nessas duas máquinas! A posição de eu ficar adormecia o meu braço...Estou nessa até hoje. Fiquei afastada quinze dias. Quando eu estava afastada, colocavam uma pessoa em uma máquina e outra em oura. Mas quando a robozinha volta, só eu sozinha nas duas...

- Por que te chamam de robozinha?

- Porque eu sou rápida, não consigo...Acho que foi a prática que fez...Conforme eu tenho a minha rapidez, me deixam nas duas máquinas...

- Onde é seu problema?

- Além de atacar o meu braço e a minha perna (tornozelo), atacou também a minha vista...

- Por que?

- É uma peça de contato muito pequena. Quer dizer, em cima daquilo tem que ter uma lâmpada muito forte, se não, você näo consegue enxergar. $A$ lâmpada afeta minha vista, porque tem problema de claridade. Então, dói o olho, dói cabeça, dói perna, dói braço...

Operária, 28 anos.

"Meu problema é no pulso. Foi lá na máquina, na seção de cabos. Também pego peso, faço bastante movimentos.

- Como é?

- A máquina é mais ou menos deste tamanho ( faz o gesto). A gente tem que regular ela, a cor dos fios- os fios vêm num rolo hiper pesado- dividir o peso...A gente faz várias coisas num dia, não faz só uma. Eu mesma corto para o timer, ventilador, brill, monocromo, 4 polos, 6 polos...

- O que você faz?

- Eu tenho que colocar (os fios) na medida na máquina. Ponho na máquina, depois eu arrumo as pontas, tem fio grosso, fino...Depois, a gente enrola (o fio), puxa e solta assim (faz o gesto). Tens uns (fios) que väo no terminal. Ai, a gente tem que pegar e fazer vários movimentas. Tem um que vai em duas máquinas; tem um que tem que soldar, mandar pra outra seção de volta. A gente era em oito (quando a empresa ficava em outra cidade). Passou para quatro. Agora, vai fazer um ano que a gente só está em duas (operárias).

- Fazendo a mesma coisa?

- Trabalhando em várias máquinas, só em duas, eu e a outra..

- A produção diminuiu ou você está indo mais rápido?

- Mais rápido. Porque eu estou trabalhando no mesmo tempo. Eu deixo a minha máquina ligada e estou trabalhando numa prensa, vamos supor. Daqui a pouco, estou soldando, a outra está na outra máquina...

- Você acha que está trabalhando mais?

- Claro que estou! Antes, eu ficava olhando a máquina, eu ajudava mas näo 
era tanto. Agora, passou para quatro, agora duas!

Operária, 21 anos

Em todos estes relatos há vários pontos em comum:

\section{a- "Muito movimento"}

Todos os trabalhadores descreveram sua atividade como uma seqüência de movimentos, principalmente de braços e mãos (mas em alguns casos, também de pés) feitos para pegar, puxar, colocar, bater, encaixar, empurrar, apertar, segurar, dobrar, enrolar, desmontar, tirar, abrir, bater, arrumar peças.

Em alguns relatos, pode-se observar também referências a condiçōes desfavoráveis em que estes movimentos foram feitos: "a prensa é alta", "a parafusadeira trepida", "o dispositivo pesa", "faço força", todos eles sugerindo inadequaçōes entre as características do posto de trabalho, das máquinas e/ou das ferramentas e as características físicas dos trabalhadores ou suas possibilidades de trabalbo.

\section{b- "Serviço muito corrido"}

Este termo apareceu em todos os relatos com significados um pouco diferentes.

Em alguns casos, significava ritmo de trabalho elevado, expresso pelo próprio volume de produção ou o número de peças exigidos por unidade de tempo:

"1300 peças por dia no solenóide"
"1800 peças por dia no torno"

"4000 peças por dia na prensa"

Nos casos em que o número de peças exigido ou produzido foi mencionado, observou-se que os ciclos de trabalho eram extremamente curtos, como, por exemplo, na montagem do escapamento: 25 segundos.

Em outros casos, "serviço muito corrido" significava diminuição de qualquer intervalo de tempo em que o trabalhador não estava diretamente produzindo. Isto acontecia seja alocando o trabalhador para outros serviços, seja lhe dando o controle de várias máquinas ao mesmo tempo.

Enfim, "serviço corrido" exprimia a manutenção da produção com redução de pessoal e portanto, aumento do ritmo de trabalho.

"a gente era em oito, passou para quatro e agora somos duas"

\section{c- "Mudança de serviço"}

Em todos os casos, os trabalhadores passaram por vários postos de trabalho. $\mathrm{A}$ explicação para esta grande rotatividade não estava apenas no afastamento do posto no qual se manifestou a dor, por uma questão de prevenção. Era uma política de organização de pessoal que privilegiava a "polivalência" dos trabalhadores, como veremos adiante.

De qualquer forma, fica evidente que o problema da "tenossinovite" não era 


\section{PRODUÇÃO}

exclusivo de um setor da empresa, mas estava difundido por vários deles

\section{d- As dores}

A descriçāo dos movimentos, enriquecida pelos gestos de trabalho realizados, estava em perfeito acordo com as queixas referidas pelos trabalhadores. Movimentos freqüentes e repetidos com o braço esquerdo causando dores no braço esquerdo; movimentos freqüentes e repetidos com o braço direito causando dores neste braço e assim por diante. $\mathrm{E}$ mudanças de serviço se acompanhando de mudanças na localização das dores.

Em relação ao diagnóstico clínico é que permanecia a dúvida. Na realidade, a "tenossinovite" era um termo geral empregado para uma série de queixas como dor e adormecimento dos membros, manifesta em graus variáveis de gravidade.

\section{Tenossinovite \\ e organização da produção}

Todos os fatores anteriormente discutidos como relevantes para a compreensāo das origens da tenossinovite, como repetitividade de movimentos e ritmos elevados de trabalho são decorrentes de uma forma de organização da produção e nos levaram a explorar melhor esse tema.

Os casos de tenossinovite nesta empresa começaram a aparecer havia alguns anos, quando a mesma estava situada em um outro município paulista (S.A.). Ao se mudar para o município onde estava no momento deste estudo, houve uma mudança na organização da produção.

Alguns aspectos desta mudança foram explicados pelos trabalhadores:

"Em S.A, a linha (de montagem) onde eu trabalhava era inteira. A montagem começava lá na ponta, cada um fazia a sua parte e colocava na esteira..Aqui (no atual município), já veio na célula. A célula é em formato de 'U'. Aí, tem as bancadas com os dispositivos em cima das mesas e cada um no seu posto. Cada um vai fazendo o seu serviço e vai passando.

- Passando como?

- Você coloca do lado. Porque a mesa, é uma mesa normal, uma encostada na outra, não tem espaço. Você faz a sua parte e coloca do lado, a outra pessoa pega e vai fazendo...Na esteira, todo o mundo ficava sentado e na célula, é todo o mundo em pé.

- O produto é o mesmo?

- É o mesmo.

- E o pessoal, aumentou ou diminuiu?

- Diminuiu.

- E vocês estão produzindo mais ou menos?

- Produzindo mais...Em S.A., eram 750 peças em cada turno. Então, daria 1500. Agora, depois que mudou para célula, eram 1200 aparelhos só num turno. $O$ outro turno, mais 1200..Aumentou muito mais!

- Por que você acha que aumentou? Ficou mais fácil de trabalhar? Vocês ficaram mais rápidos?

- Fica mais rápido". 
Esta primeira descriçāo já mostrava algumas características da nova organização da produção: mudança do sistema de "esteira rolante" para "células de produção".

Os próximos relatos davam outras informações importantes:

"Eles fizeram estas células para falar que era para fazer de uma em uma peça. Era "escravo de jó". Mas na realidade não foi isso, näo funcionou nada dessa forma...Então, eles começaram a aumentar o ritmo.

- Por que aumentou o ritmo?

- As peças vem vindo de um lado e você tem que fazer a produção que eles pedem. $O$ pessoal puxa lá na frente, começa pelo motor... motor está chegando, as peças para a montagem...Se ficam peças paradas ali, porque aqui você está parado, ou está faltando para você, já vem alguém ajudar você. Tem que acompanhar a linha. É a produtividade!

- Como é que você sabe o que você tem para fazer?

- Tem KANBAN.

- Como é o KANBAN?

- KANBAN é um quadro com a quantidade das peças que cada seção produz, o que você usa. Tem um cartão com a descriçäo da peça e a quantidade de peças ali naquele quadro. Conforme vai tirando o cartão, vai produzindo..."

Kanban é um sistema de controle da produção comandado através do uso de placas ou cartōes (em japonês, kanban significa placa) onde somente após o consumo das peças na linha de montagem é dada uma autorização de fabricação de um novo lote de peças. Assim, é a montagem quem determina o ritmo e as quantidades a serem produzidas.

A descrição do processo e o termo KANBAN levam a crer que o novo sistema empregado se baseava no princípio "just in time" ("no momento certo"), que é uma "filosofia" de produção inspirada no "modelo" japonês. Este sistema, utilizado em indústrias de produção em série, pretendia ser uma resposta eficaz às variações das demandas do mercado, em qualidade e quantidade, através de um aumento da "flexibilidade" na sua estrutura de produção. Seu princípio é produzir o que é necessário, na quantidade necessária e no momento certo (DIEESE,1994). Para isto, a empresa passava por mudanças no projeto de produção e na organização da mão de obra. Em relação ao projeto, havia um novo reagrupamento das máquinas, em "células" ou "ilhas". Do ponto de vista da mão de obra, o sistema supõe uma total "polivalência" dos trabalhadores.

Na empresa em questão, o novo sistema foi apresentado aos trabaliadores como Escravos de Jó, numa clara alusão ao jogo infantil que todos conhecem (o que não exclui outras interpretaçóes para a palavra escravos...).

$\mathrm{Na}$ realidade, ele parece ter provocado os seguintes efeitos negativos:

a - intensificação do trabalho, pois a produção se manteve ou aumentou apesar 
da redução do número de trabalhadores. Isto ocorreu graças a vá rios motivos: a diminuição dos intervalos de tempo em que os operários não estavam diretamente ocupados na produção (por exemplo, no sistema de esteira rolante, os operários podiam acumular algumas peças e deixar a linba de montagem, por alguns momentos, para tomar café; já no sistema de célula, o café passou a ser servido no próprio posto de trabalho, para que a produção não fosse interrompida). E por se dar, a um mesmo operário, o controle de várias máquinas, simultaneamente ou de acordo com a conveniência da empresa em cada momento.

b - a mobilidade da mão de obra dentro da empresa se fez acompanhar de uma mobilidade também dos efeitos lesivos do trabalho. Assim, a mudança de serviço foi a companhada de uma mudança na localização das dores.

c - agravamento de algumas condiçōes de trabalho, como a exigência de trabalhar em pé para os trabalhadores no sistema de célula ao invés de sentados, como no sistema anterior.

Estes fatos, decorrentes da nova organização da produçāo, devem ter contribuído para aumentar as possibilidades de se adquirir a "tenossinovite", já existentes no sistema anterior.

Uma delas era o modo de se calcular o número de peças produzido:
"Conforme o pessoal vai trabalhando, se o pessoal vai desenvolvendo bem, eles aumentam (o ritmo).

- Desenvolvendo bem o que?

- Te pedem 100 peças por hora. Se você faz 110, ai eles sabem que você vai dar mais. Entäo, conforme você vai desenvolvendo a mais, eles pedem mais ainda."

"- Quem pede para ir rápido?

- Sempre quem dá a quantidade de peças que tem que fazer na linha é o lider."

"O lema do encarregado na seção é "manda bala" e "dá o gás".

Este sistema é perverso porque ao mesmo tempo que estimula a rapidez, pune os trabalhadores mais rápidos, que adquirem as doenças.

\section{Tenossinovite}

e realocação do pessoal

Os relatos dos trabalhadores confirmaram um fato já amplamente conhecido: a dificuldade de diagnóstico e tratamento médico do problema. Vários deles contaram suas inúmeras iniciativas de diagnosticar e controlar a tenossinovite, muitas delas discordantes entre si e, em geral, sem resultados práticos concretos.

A empresa também estava tendo dificuldade para realocar o pessoal com tenossinovite e amenizar o problema. A 
recomendação dada a alguns operários de diminuir o seu ritmo, de "ir mais devagar" nāo tem sentido. De fato, o ritmo de trabalho elevado, adquirido na prática profissional e estimulado pelo próprio sistema de produção, se "interioriza" nos trabalhadores, os gestos se automatizam e é muito difícil, se não impossível, diminuí-lo (Leplat, 1957). Além disso, neste tipo de sistema ocorre uma "autoaceleraçāo", já descrita em 1956 por Le Guillant e colaboradores, em seu célebre estudo sobre telefonistas (Le Guillant e cols, 1984), também verificado em estudos de outras categorias de trabalhadores, como cita Wisner falando da densidade do trabalho (Wisner,1994) e mais recentemente estudada e interpretada por Dejours (1986) como um dos componentes de um mecanismo de defesa psicológica contra organizaçōes de trabalho cujos imperativos de velocidade gestual são dominantes

Por outro lado, não encontramos nenhuma iniciativa, por parte da empresa, de instaurar pausas durante a jornada de trabalho. Estas pausas, interrompendo os movimentos, são preconizadas para minimizar os problema. Atualmente, sua obrigatoriedade consta do item $17.6 .3 \mathrm{da}$ NR17- Norma Regulamentadora de Ergonomia (MTPS, 1990):

"nas atividades que exijam sobrecargas muscular estática ou dinâmica do pescoço, ombros, dorso e membros superiores ou inferiores e a partir da análise ergonômica do trabalho...devem ser incluidas pausas para descanso".

\section{Conclusões}

A primeira conclusão deste estudo refere-se ao método utilizado, que se mostrou adequado para se conhecer melhor as origens das queixas de tenossinovite. Em poucas horas de reunião obtivemos informaçōes numerosas $e$ ricas, dificilmente obtidas em igual tempo através de observações diretas. Os trabalhadores participaram com muito empenho e o fato de poderem falar, coletivamente, sobre a sua atividade valorizou o trabalho de cada um e mostrou pontos em comum até então não conhecidos, enriquecendo a compreensāo do processo de trabalho em que estavam envolvidos. A participação de um diretor do Sindicato nas reuniōes foi importante, pois ampliou sua visão do problema e relativizou o papel do técnico que, ao invés de ser encarado como aquele que dá as soluçōes passa a ser visto como aquele que pode contribuir para o esclarecimento de um problema, num processo que envolve outros tipos de conhecimentos.

Quanto aos resultados, vale a pena resumi-los brevemente. A "tenossinovite" era um termo geral, utilizado para várias queixas de dores em membros superiores ou inferiores. Estas queixas foram relatadas por trabalhadores de ambos os sexos e principalmente por trabalhadores jovens, de vá rios setores da empresa que, em comum, executavam tarefas que exigiam movimentos localizados, estereotipados e repetidos dos braços ou pernas, e um ritmo elevado de trabalho. A postura corporal exigida, a força empregada, a forma e o 
modo de utilização das ferramentas parecem ter sido agravantes da sịtuação. No entanto, ficou evidente que as novas formas de organização da produçāo, com a introduçāo de "células" de produção, Kanban e "polivalência" dos operários contribuiu para agravar as condiçōes de trabalbo e aumentar os problemas. A rotação de postos de trabalho gerou uma rotação das dores e seu agravamento. $\mathrm{Na}$ verdade, houve uma intensificação do trabalho, com aumento de ritmo, por diminuição dos intervalos entre operações, atribuição de mais tarefas ao mesmo trabalhador e diminuição de pessoal.

Estes resultados suscitam vários questionamentos e consideraçōes.

Se se focalizar a situação particular descrita, fica claro quão limitados têm sido os estudos que se detém em medidas sofisticadas de gestos e de equipamentos e algumas recomendaçōes preconizadas para se amenizar os casos de L.E.R., como a rotatividade de funçōes.

Ta mbém ficam claros os limites das teorias mais difundidas no Brasil sobre a gênese das L.E.R. que falam de uma justaposição de "fatores", em geral mal definidos (o termo psicossocial, por exemplo, aparece com diferentes conceituações, sempre imprecisas) e de igual peso, ocultando suas relaçōes.

Ao mesmo tempo aponta para a necessidade de se desmistificar alguns termos utilizados correntemente, através da busca de uma conceituação mais precisa.
Estamos nos referindo mais especificamente ao conceito de produtividade.

A produtividade é uma relação, uma razão entre o que é produzido e os meios necessários para isto. Os dois termos desta fraçāo podem incluir parâmetros diferentes. Assim, por exemplo, o numerador pode ser o número de produtos fabricados e o denominador, o número de empregados, ou o faturamento, ou o volume de capital, etc.

A medida mais comum da produtividade se refere à chamada produtividade do trabalho (para diferenciá-la da produtividade do capital), em geral expressa pelo volume produzido por pessoal empregado.

Sendo uma fração, a produtividade pode aumentar ou diminuir dependendo do aumento ou diminuição de seus dois termos.

Consideremos aqui a produtividade (P) como uma relação entre o volume da produçāo (v) e o número de empregados (e) e vejamos do que ela depende.

$$
\mathbf{P}=\mathbf{v} / \mathbf{e}
$$

A produtividade (P) pode aumentar seja pelo aumento do volume de produçāo (v) seja pela diminuição do número de empregados (e). Inversamente, $(\mathbf{P})$ pode diminuir se o (v) diminuir ou (e) aumentar.

Como se pode aumentar o volume da produção (v)? Basicamente através de três formas: 
1- através do aumento da duração da jornada. Se em 8 horas, um trabalhador produz 10 peças, em 10 horas ele produzirá mais peças, aumentando (v).

2- através do aumento do ritmo de trabalho. Se em 8 horas um trabalbador produz 10 peças, a um ritmo portanto de 1,25 peças por hord, e se aumentarmos seu ritmo para 2 peças por hora, ele produzirá, nas mesmas 8 horas, 16 peças.

3- através de mudanças tecnológicas. Se um trabalhador com sua antiga máquina produzia 10 peças, a utilização de uma máquina mais potente pode fazê-lo produzir 20 peças

Em todos estes exemplos, houve um aumento da produtividade $(\mathbf{P})$. No entanto, seus efeitos foram diferentes para $o$ trabalhador na sua situação de trabalho. Se o aumento da produtividade foi decorrente de um aumento da sua jomada ou de um ritmo mais elevado de trabalho, o trabalhador fez mais esforço. Só no terceiro caso, se o aumento da produtividade foi decorrente de uma melhoria das condições da máquina, o aumento da produtividade não teve, necessariamente, por efeito um aumento do esforço.

E lógico que numa dada situação de trabalho, todos estes fatores em geral atuam simultaneamente e é difícil separá-los. No entanto, é claro que há, teoricamente, uma diferença entre o aumento da produtividade que decorre de melhorias na situaçāo de trabalho e o aumento da produtividade decorrente de uma piora na situação de trabalho, porque exige mais do trabalhador.

Em todas as situaçōes em que o aumento da produtividade é decorrente de uma maior exigência para o trabalhador, de modo que ele tenha que trabalhar mais numa dada unidade de tempo ou, usando as palavras de Wisner (1994), que o seu trabalho fique mais denso, há uma intensificação do trabalho.

Seguindo o raciocínio até aquj exposto, há pelo menos duas formas de se intensificar o trabalho: diminuindo-se o número de empregados e mantendo-se a produçāo ou, com o mesmo número de empregados, aumentando-se o seu ritmo de trabalho.

É importante, portanto, quando se fala em aumento de produtividade, precisar do que se está falando e sobretudo não confundir aumento de produtividade com intensificação do trabalho, "a produtividade não desejada" pelos trabalhadores (DIEESE,1994).

Um dos efeitos dos programas de "restruturação produtiva", no Brasil, tem sido uma intensificaçāo do trabalbo, detectada em vários estudos, principalmente naqueles onde trabalhadores diretamente envolvidos na produção são entrevistados, com diferentes instrumentos metodológicos (DIEESE, 1996).

No mundo também tem acontecido a mesma coisa, como mostram vários estudos, em particular um, realizado em 


\section{PRODUÇÃO}

1994 pela Organização Internacional do Trabalho, sobre a situação das indústrias mecânicas, aí compreendidas a indústria armamentista, a aeroespacial, a da construção naval, a automobilística, a de máquinas ferramentas $e$ a indústria de artigos elétricos, eletrônicos e informáticos (OIT,1994). No capítulo "conseqüências para as condicões de trabalho das novas formas de organizacão da producão", o relatório apresenta resultados de diferentes estudos realizados em vários países, dos quais os trechos a seguir dão uma mostra:

" $E m$ diversos estudos britânicos se chegou à conclusão de que raramente se dá prioridade à polivalência. Pelo contrário, a principal razão de ser da reorganização do trabalho, qualificado ou não, tem sido a redução da "porosidade", isto é, das pausas, dos períodos de descanso e do tempo de espera, $e$ a intensificação do trabalho." (grifos nossos).

"Na fábrica de alternadores e motores de Lucas Electrical, de Birmingham, se reorganizou a fábrica em forma de $U$ interconectados. Em cada célula, se estabeleceu uma flexibilidade laboral em relação às diferentes tarefas. Os tradicionais departamentos de controle da produção e seguimento de peças durante a fabricação foram fechados e se reduziu o efetivo a 300 trabalhadores. Nāo consta que se procedeu a uma grande requalificação dos que restaram nem que houve melhoria de sua competência, mas, em contrapartida, houve uma intensificação do trabalho. Segundo um delegado sindical experimentado "o trabalho é exatamente igual ao anterior, porém mais duro"2 (grifos nossos)

“Em uma reunião promovida pela OIT em novembro de 1992, especialistas tentaram determinar se os sistemas de produção ajustada cumprem verdadeiramente sua promessa de combinar um maior rendimento com maior qualificação do emprego ou se este "ajuste" implica inevitavelmente uma intensificação do trabalho e mudanças de pessoal. No estudo de um especialista, baseado na experiência de várias empresas mecânicas alemās, se chegava à conclusão que:

"...quando se pede concretamente aos promotores da produção ajustada e aos diretamente afetados por ela que digam o que significa para eles, nas condições reais de sua esfera de atuação, resulta evidente que ela é considerada como uma espécie de instrumento supremo de reducão de custos...Em conjunto, os trabalhadores têm muito a perder e pouco a ganhar com a implantação de um sistema de produção ajustada na empresa. São relativamente poucos os que têm a probabilidade de alcançar a vida de trabalho verdadeiramente enriquecida que propõe a demagogia deste sistema" ${ }^{\text {. (grifos nossos) }}$

É interessante notar que a referência à redução de custos acima citada também foi citada por um gerente da empresa em que fizemos este estudo, que recentemente transferiu uma parte de suas atividades para o Nordeste, conforme reportagem da imprensa (OESP,1997): 
"Viemos para cá por uma questão de custos de produçāo.. Aqui temos chance de competir com os chineses, que pagam salários de U\$ 90,00 e mais nada aos seus operários...A atitude do nordestino em relação ao trabalho na indústria é muito diferente daquela com a qual nos acostumamos em São Paulo. Eles são muito francos, deixam claro quando não gostam, mas são sobretudo receptivos. Se têm uma meta de produtividade, perseguem até conseguir superá-la. $\hat{E}$ diferente do caso paulista. Lá, se o sujeito ultrapassa o padrão de produtividade, acaba na comissão de fábrica. Aqui, não tem nada disso."

A reportagem também cita que "desde $o$ início do ano, a equipe que o gerente coordena está produzindo 220 a 340 motores por hora. Na fábrica similar em São Paulo, o máximo é de 180 peças prontas por hora."

Introduzir na discussão técnica o tema da intensificação do trabalho contribui para entender a "epidemia" mundial das L.E.R pois embora os estudos estejam avançando, a gênese da L.E.R continua a ser um desafio para os pesquisadores das mais diferentes áreas, em vários países. Um exemplo sintomático aconteceu no Congresso Internacional de Psicopatologia e Psicodinâmica do Trabalho, realizado em Paris em 1997, que elegeu as L.E.R.chamadas de "patologias de hipersolicitação", como um dos temas centrais, discutido por especialistas de diferentes áreas.
Também coloca em pauta, com nova força, uma questão antiga e bastante conhecida do movimento dos trabalhadores: o controle dos ritmos de trabalho. Além de suas relaçōes claras com a saúde dos trabalhadores, o tema da intensificação do trabalbo está na ordem do dia na discussāo das propostas de diminuição de jornada, como estratégia para se combater o desemprego. Como diz Volkoff (1994), a duração e a intensidade do trabalho são indissociáveis, principalmente porque a redução do tempo de trabalho por via legal certamente se acompanhará de pressões para intensificar ainda mais o trabalho.

Recebido em: 18/08/97 Recebido após modificaçōes: 24/08/98 Aceito após revisão: $15 / 10 / 98$ Publicado em: 25/03/99

\section{Referências bibliográficas}

Assunção, A.A. e Rocha, L.E. (1993). Agora, ... até namorar fica difícil: uma história de lesões por esforços repetitivos. In.Buscchinelli, J.T.P., Rocha, L.E., e Rigotto, R.M..(orgs). Isto é trabalho de gente? Vida, doenca e trabalho no Brasil. Sāo Paulo: Vozes.

Barreira, T.H.C. (1994). Fatores de risco de lesōes por esforços repetitivos em uma atividade manual. Tese de Mestrado, Instituto de Psicologia, USP.

(1995). Análise da 


\section{PRODUÇĀO}

atividade de postos de trabalho nas linhas de ensacamento de uma empresa. Relatório elaborado por solicitação do Ministćrio Público. São Paulo: FUNDACENTRO.

Cândido,V.G. e Neves, M.A. (1997). Gênero, trabalho e saúde: um estudo de caso de LER numa empresa do setor metalúrgico. In Antunes Lima, M.E., Garcia de Araújo, J.N. e Antunes Lima, F.P (orgs). LER: dimensōes ergonômicas e psicossociais. Belo Horizonte: Health.

Crespo Merlo, A.R. (1997). Technologie de l'information et maladie du travail: le cas du traitement de masse de données dans l'informatique brésilienne. Actes du Colloque International de Psychodynamique et Psychopathologie du Travail. Paris, tome I: 253-264

Dejours, C. (1986). Souffrance au travail et racisme. In La societé française et l'immigration maghrébine. Questions et perspectives culturelles, ATMF-IRETEP, vol.1:123-148

(1988). A loucura do trabalho: ensaio de psicopatologia do trabalho. Trad. Ana Isabel Paraguay e Lúcia Leal Ferreira. São Paulo: Cortez/ Oboré.

Departamento Intersindical de Estatística e Estudos Sócio Econômicos /DIEESE (1994). Trabalho e restruturação produtiva: dez anos de linha de montagem.

(1996) .Pesquisa Perfil

Profissional dos Metalúrgicos de
Guarulhos, Aruiá, Mairiporã e Santa Isabel. Relatório final.

Echternacht, E.H. (1997). Atividades de serviço e patologia do trabalho repetitivorelações mediadas por sistemas informacionais organizados sob princípios tayloristas. Seminário internacional o trabalho humano com sistemas informatizados no setor de serviços. São Paulo: Escola Politécnica da USP.

Ferreira, L.L. (1992). Lesões por esforcos repetitivos com rítmos elevados numa empresa metalúrgica. Relatório. São Paulo: FUNDACENTRO.

(1993). Análise Coletiva do Trabalho. Revista Brasileira de Saúde Ocupacional, 21 (78): 7-19.

(1997). Des

rapports entre la psychodynamique du travail et l'analyse collective du travail. Actes du Colloque International de Psychodynamique et Psychopathologie du Travail.Paris, tome II: 191-199.

Le Guillant, Roelens, Begoin, Béquart, Hansen e Lebreton (1984) A neurose das telefonistas. Trad Denise Monetti e Leda L. Ferreira. Revista Brasileira de Saúde Ocupacional, 12 (47):7-11.

Leplat, J. (1959). Quelques aspects de la vitesse dans le travail des ouvriers specialisés. Bulletin du Centre d'Etudes et Recherches Psychotechniques-CERP, tome VIII: 55-64. 
Lima, F.P.A. e cols.(1997). A produção das lesões por esforços repetitivos num restaurante universitário: análise ergonômica e psicossocial. In Antunes Lima, M.E.,Garcia de Araújo, J.N. e Antunes Lima, F.P (ongs). LER: dimensōes ergonômicas e psicossocia is. Belo Horizonte: Health.

Lima, M.E.A. (1997). A LER no setor Bancário. In Antunes Lima, M.E.,Garcia de Araújo, J.N. e Antunes Lima, F.P (orgs). LER: dimensões ergonômicas e psicossociais. Belo Horizonte: Health.

Ministério da Previdência Social/ Instituto Nacional de Seguro Social (1993). LER, Lesões por Esforcos RepetitivosNormas Técnicas para avaliação da incapacidade. Brasília.

Ministério do Trabalho e da Previdência Social (1990) Norma Regulamentadora $n^{2}$ 17-Ergonomia. Brasília.

O Estado de São Paulo (1997)--Caderno 2, Especial Domingo. O Nordeste avança. 06/07/97.

Organizaçāo Internacional do Trabalho (1994). Situación reciente en las industrias mecánicas. Comission de Industrias Mecánicas, decimo tercera reunión, Informe I, Genebra.

Ribeiro, H.P. (1995). Estado atual das Lesōes por Esforços Repetitivos (LER) no Banco do Estado de São Paulo S.A.BANESPA. Caderno de Saúde/ AFUBESP, 1(1) junho.
Sznelwar, L. e Masseti, M.(1997). La spirale de la souffrance- les lésions par efforts répétitifs (étude de cas auprès de travailleurs du secteur des services). Actes du Colloque International de Psychodynamique et Psychopathologie du Travail.Paris, tome I: 265-276.

Volkoff, S. (1994) Maîtriser l'intensité du travail. In Agir ensemble contre le chômage, França, Editions Sylepse.

Wisner, A.( 1994). A inteligência no trabalho. Textos selecionados de ergonomia. Trad. Roberto L.Ferreira, São Paulo, FUNDACENTRO.

\section{Notas}

1. tenossinovite: inflamaçāo dos tendōes e membranas sinoviais. No Brasil, foi considerada doença do trabalho em 1987. Atualmente, é uma das formas clínicas das Lesōes por Esforços Repetitivos (L.E.R.), reconhecida desde 1993 pela Previdência Social como doença do trabalho.

2. P. Turnbull: "The limits to Japanization- just-in-time, labour relations and the UK automotive industry". In $\mathrm{New}$ technology, work and employment. (Blackwell, Oxford, UK) 1988, pags 12 e 13.

3. P. Cooke: "The experience of German engineering firms in applying lean production methods", documento preparado para uma conferência organizada pelo Instituto Internacional de Estudos Laborais (OIT, Genebra, novembro de 1992) 